\title{
Renoprotective Effect of Losartan in Comparison to Amlodipine in Patients with Chronic Kidney Disease and Hypertension-a Report of the Japanese Losartan Therapy Intended for the Global Renal Protection in Hypertensive Patients (JLIGHT) Study
}

\author{
Yasuhiko IINO ${ }^{* 1}$, Matsuhiko HAYASHI ${ }^{* 2}$, Tetsuya KAWAMURA ${ }^{* 3}$, Tatsuo SHIIGAI ${ }^{* 4}$, \\ Yasuhiko TOMINO ${ }^{* 5}$, Kenichi YAMADA*6, Takeyuki KITAJIMA*3, Terukuni IDEURA*7, \\ Akio KOYAMA *8, Tetsuzo SUGISAKI ${ }^{* 9}$, Hiromichi SUZUKI ${ }^{* 10}$, Satoshi UMEMURA*11, \\ Yoshindo KAWAGUCHI ${ }^{\# 1}$, Shunya UCHIDA ${ }^{\# 2}$, Michio KUWAHARA \#3, and \\ Tsutomu YAMAZAKI\#4, for the Japanese Losartan Therapy Intended for \\ the Global Renal Protection in Hypertensive Patients (JLIGHT) Study Investigators
}

\begin{abstract}
A 12-month, multicenter (57 clinical institutions), randomized, open-labeled trial was undertaken to compare the efficacy of the angiotensin II receptor antagonist losartan and the calcium channel blocker amlodipine in patients with proteinuric chronic kidney disease (CKD) and hypertension. A total of 117 patients (79, chronic glomerulonephritis; 14 , diabetic nephropathy; 24, other $C K D$ ) were randomly allocated into two treatment groups. Losartan and amlodipine exerted the same efficacy for blood pressure (BP) control; however, losartan significantly reduced the 24-h urinary protein excretion at months 3,6 , and 12 , with the reduction of $20.7 \%, 35.2 \%, 35.8 \%$, whereas amlodipine did not change the amount of proteinuria over the 12-month study period. When patients were stratified into groups according to the level of BP control at 3 months, the reduction in urinary protein excretion by losartan was evident in the group for which a BP of $<140 / 90 \mathrm{mmHg}$ was achieved, as well as in the group for which the goal BP $(<130 / 85 \mathrm{mmHg})$ for treatment of CKD was not achieved. When patients were stratified according to baseline urinary protein excretion, those with $\geq \mathbf{2}$ g/day showed a reduction in proteinuria by losartan of $23.3 \%, 39.4 \%$, and $47.9 \%$ at months 3,6 , and 12 , and those with $<2 \mathrm{~g}$ /day showed a reduction of $18.5 \%$ and $31.2 \%$ at months 3 and 6 , respectively. No fatal adverse
\end{abstract}

\footnotetext{
* Coordinating Committee. ${ }^{*}$ Independent Data-Monitoring Committee.

From the ${ }^{*}$ Second Department of Medicine, Nippon Medical School, Tokyo, Japan, ${ }^{* 2}$ Department of Internal Medicine, Keio University School of Medicine, Tokyo, Japan, ${ }^{*}$ Department of Internal Medicine, Jikei University School of Medicine, Tokyo, Japan, ${ }^{*}$ Department of Internal Medicine, Toride Kyodo General Hospital, Toride, Japan, ${ }^{* 5}$ Department of Internal Medicine, Juntendo University School of Medicine, Tokyo, Japan, ${ }^{* 6}$ Department of Internal Medicine, Sakura National Hospital, Sakura, Japan, ${ }^{* 7}$ Division of Nephrology, Showa University Fujigaoka Hospital, Yokohama, Japan, ${ }^{* 8}$ Department of Internal Medicine, University of Tsukuba, Tsukuba, Japan, ${ }^{* 9}$ Department of Nephrology, Showa University School of Medicine, Tokyo, Japan, ${ }^{* 10}$ Department of Nephrology, Saitama Medical School, Saitama, Japan, ${ }^{* 11}$ Department of Medical Science and Cardiorenal Medicine, Yokohama City University Postgraduate School of Medicine, Yokohama, Japan, \#1 Department of Internal Medicine, Jikei University School of Medicine, Tokyo, Japan, ${ }^{\# 2}$ Department of Internal Medicine, Teikyo University School of Medicine, Tokyo, Japan, ${ }^{\# 3}$ Homeostasis Medicine and Nephrology, Tokyo Medical and Dental University, Tokyo, Japan, and ${ }^{\# 4}$ Graduate School of Medicine, University of Tokyo, Tokyo, Japan. Address for Reprints: Yasuhiko Iino, M.D., Second Department of Medicine, Nippon Medical School, 1-1-5, Sendagi, Bunkyo-ku, Tokyo 113-8603, Japan. E-mail: iinoy@nms.ac.jp

Received July 31, 2003; Accepted in revised form October 9, 2003.
} 


\begin{abstract}
events were experienced in either drug group. We conclude that losartan reduced proteinuria in patients with CKD and hypertension. This positive effect may contribute to the renal protective benefit of losartan, and is beyond the magnitude of BP control. (Hypertens Res 2004; 27: 21-30)
\end{abstract}

Key Words: losartan, angiotensin, proteinuria, hypertension, renoprotection

\section{Introduction}

On the basis of understanding the role of angiotensin II in circulation and renal functions, the relevance of intervention of the renin-angiotensin system (RAS) for therapy of hypertension and kidney diseases has so far been extensively discussed $(1,2)$. High blood pressure (BP) strongly affects the structure and functions of nephrons, and inversely, impaired renal function elevates the systemic BP level in patients with kidney diseases. Angiotensin converting enzyme (ACE) inhibitors are now one of the most frequently used drugs for hypertension, and a number of evidences are available with regard to the effect of ACE inhibition to ameliorate kidney diseases, especially proteinuria as a symptom (3). Indeed, in many clinical studies dealing with kidney diseases, proteinuria has been adopted as a surrogate endpoint, because proteinuria is not merely a marker of permselectivity of the glomerular membrane, but is toxic to the kidney per se, and plays a key role in the progression of kidney diseases, eventually leading to end-stage renal disease (ESRD) (4-7).

With reference to the effect of ACE inhibitors, the use of angiotensin II receptor antagonists for the treatment of kidney diseases has also been discussed. The RENAAL study, an international multicenter clinical trial of the angiotensin II receptor antagonist losartan, was published in 2001 (8). This trial studied the effect of losartan in patients with type 2 diabetic nephropathy. The results clearly demonstrated that losartan retarded the elevation of serum creatinine and decreased the rate of onset of ESRD. On the other hand, the effects of intervention of the actions of angiotensin II in patients with non-diabetic chronic kidney disease (CKD) and hypertension has been still a subject of debate with regard to relation to BP lowering effect. Any pharmacotherapy to lower BP may be effective for protection of renal functions; however, whether blockade of angiotensin II receptors confers renal protection in excess of that due to BP control has not been clearly answered. There is thus need of accumulation of evidences of comparative study with other classes of antihypertensive drugs in patients with CKD and hypertension. For this reason, we have performed a 12-month study comparing the effects of the angiotensin II receptor antagonist losartan and the calcium channel blocker amlodipine. A portion of the results were previously disclosed as an interim report at 3 months (9) with the full analysis set (FAS) (10). We here report our final results based on the final selection of patients by the Coordinating Committee. Our findings show that, although losartan and amlodipine exerted the same degree of BP control, only losartan induced a signifi- cant reduction in urinary protein excretion over the 12month observation period.

\section{Methods}

This study was a 12-month, multicenter, randomized, openlabeled, clinical trial designed to compare the effect of the angiotensin II receptor antagonist losartan and the calcium channel blocker amlodipine to reduce proteinuria in patients with CKD and hypertension. Fifty-seven affiliated clinics in Japan contributed to this study. The overall design of the study has been described previously in an interim report presented at 3 months (9). Males and female outpatients, aged 20-74 years, who had CKD and hypertension and who met the following criteria during the 8-week pretreatment screening period were eligible for the study:

1) CKD: serum creatinine (Scr) levels of $1.5 \leq \mathrm{Scr}<$ $3.0 \mathrm{mg} / \mathrm{dl}$ in males of body weight $(\mathrm{BW}) \geq 60 \mathrm{~kg}$, and of $1.3 \leq \mathrm{Scr}<3.0 \mathrm{mg} / \mathrm{dl}$ in females, or males of $\mathrm{BW}<60 \mathrm{~kg}$.

2) Hypertension: systolic $\mathrm{BP}(\mathrm{SBP}) \geq 140 \mathrm{mmHg}$ or diastolic $\mathrm{BP}(\mathrm{DBP}) \geq 90 \mathrm{mmHg}$ as measured in a sitting position at least two separate times at their visits to clinics.

3) Proteinuria: urinary protein excretion of $\geq 0.5 \mathrm{~g} / \mathrm{day}$.

The overview of study design is shown in Fig. 1. The randomization method was modified by dynamic balancing for Scr, the 24-h urinary protein excretion that was measured at the time of registration, and presence or absence of diabetic nephropathy, so that patients were allocated to the two groups avoiding significant difference of baseline characteristics in average. Patients of the two groups received either losartan $25 \mathrm{mg}$ as a starting dose to up to $100 \mathrm{mg}$ once daily, or amlodipine $2.5 \mathrm{mg}$ as a starting dose to up to $5 \mathrm{mg}$ once daily, respectively. However, in cases in which a patient's compliance was judged by investigator(s) to be sufficiently good for the administration of a higher dose, either $50 \mathrm{mg}$ of losartan or $5 \mathrm{mg}$ of amlodipine was adopted as a starting dose.

The target BP was $<130 / 85 \mathrm{mmHg}$, and patients were not allowed combination therapy with other antihypertensive agents during the first 3 months. However, after 3 months, if a BP of $<130 / 85 \mathrm{mmHg}$ was not achieved, antihypertensive combination therapy with $\alpha$-blockers, $\beta$-blockers, $\alpha / \beta$ blockers, diuretics (excepting potassium-sparing diuretics), and other calcium channel blockers were considered as appropriate. Guidance was given to patients to maintain their usual diet, especially for those under dietary restrictions. The study protocol was reviewed and approved by the Institutional Review Boards of all clinics contributing to the study. Written informed consent was obtained from all enrolled pa- 
Table 1. Baseline Characteristics of Patients Enrolled in the Study

\begin{tabular}{|c|c|c|c|}
\hline & Losartan group & Amlodipine group & $p$ value \\
\hline$N$ & 58 & 59 & \\
\hline Age (years) & $55.7 \pm 13.6$ & $57.5 \pm 11.9$ & $\mathrm{NS}^{*}$ \\
\hline Male/female & $36 / 22$ & $41 / 18$ & $\mathrm{NS}^{\dagger}$ \\
\hline BMI $\left(\mathrm{kg} / \mathrm{m}^{2}\right)$ & $23.9 \pm 3.7$ & $22.9 \pm 3.2$ & $\mathrm{NS}^{*}$ \\
\hline Systolic BP (mmHg) & $156.5 \pm 12.2$ & $155.4 \pm 13.5$ & $\mathrm{NS}^{*}$ \\
\hline Diastolic BP (mmHg) & $94.0 \pm 9.2$ & $93.5 \pm 8.6$ & $\mathrm{NS}^{*}$ \\
\hline Serum creatinine $(\mathrm{mg} / \mathrm{dl})$ & $2.04 \pm 0.48$ & $1.97 \pm 0.52$ & $\mathrm{NS}^{*}$ \\
\hline Urinary protein (g/day) & $2.85 \pm 2.65$ & $2.50 \pm 2.07$ & $\mathrm{NS}^{*}$ \\
\hline Serum albumin $(\mathrm{g} / \mathrm{dl})$ & $3.79 \pm 0.48$ & $3.80 \pm 0.47$ & $\mathrm{NS}^{*}$ \\
\hline \multicolumn{4}{|l|}{ Diagnoses (No. of patients) } \\
\hline Chronic glomerulonephritis & $38\left(11^{\#}\right)$ & $41\left(12^{\#}\right)$ & \\
\hline Diabetic nephropathy & 7 & 7 & \\
\hline Hypertensive nephrosclerosis & 11 & 9 & \\
\hline Tubulointerstitial nephritis & 1 & 0 & \\
\hline Polycystic kidney disease & 1 & 0 & \\
\hline Renal amyloidosis & 0 & 1 & \\
\hline Castleman's disease & 0 & 1 & \\
\hline
\end{tabular}

Mean \pm SD. ${ }^{*}$ Unpaired $t$-test $;{ }^{\dagger}$ Fisher's exact test. ${ }^{\#}$ IgA nephropathy. BMI, body mass index; BP, blood pressure.

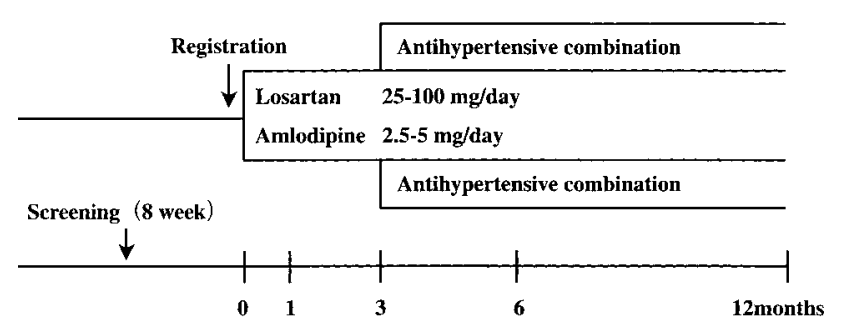

Fig. 1. Study design for treatment of patients with proteinuric CKD and hypertension. Antihypertensive combination therapy was allowed after the first 3 months, if necessary. For this alternation, the target goal BP setting was $<130 / 85 \mathrm{mmHg}$.

tients.

Exclusion criteria were as follows:

1) $\mathrm{DBP} \geq 120 \mathrm{mmHg}$.

2) Renovascular hypertension or endocrine hypertension.

3) BP control treatment with antihypertensive agent(s).

4) Patients in whom antianxiety drugs could not be discontinued.

5) Pregnancy, possibility of pregnancy, or in a period of lactation.

6) Patients that the chief investigator judged not to be eligible.

BP was measured at patients' visit to the clinic with the patient in a sitting position.

A 24-h urine collection was performed from 8:00 AM of the day before to 8:00 AM of the day of the clinic visit, and was used to obtain the 24-h urine volume, urinary protein excretion, urinary creatinine level, and the amount of sodium excretion. The creatinine clearance $(\mathrm{Ccr})$ was calculated as $\mathrm{Ccr}=\mathrm{Ucr} \times V / \mathrm{Scr} \times 1.73 / A$, where $\mathrm{Ccr}$ is the creatinine clearance $(\mathrm{ml} / \mathrm{min}), \mathrm{Ucr}$ is the urinary creatine $(\mathrm{mg} / \mathrm{dl}), V$ is the urine volume $(\mathrm{ml} / \mathrm{min}), \mathrm{Scr}$ is the serum creatine $(\mathrm{mg} / \mathrm{dl})$, and $A$ is the body surface area. The rate of renal impairment as a function of time was expressed with a reciprocal slope of Scr $(1 / \mathrm{Scr})$.

Protein intake was estimated by measurement of urea nitrogen plus protein concentration using the following formula: Protein intake $(\mathrm{g} /$ day $)=[$ urinary urea nitrogen $(\mathrm{g} /$ day $)+$ $0.031(\mathrm{~g}) \times \mathrm{BW}(\mathrm{kg})] \times 6.25+$ urinary protein excretion $(\mathrm{g} /$ day $)$ (11). Sodium chloride $(\mathrm{NaCl})$ intake was measured by $\mathrm{NaCl}$ concentrations in the collected urine using the following formula: $\mathrm{NaCl}$ intake $(\mathrm{g} /$ day $)=$ urinary sodium excretion (mEq/day)/17.

All values were expressed as the mean \pm SD. The baseline characteristics of the enrolled patients were tested for comparability between the losartan group and the amlodipine group using unpaired $t$-test or Fisher's exact test. The differences in changes in SBP and DBP between the two groups were tested by repeated-measures analysis of variance with treatment effect, period effect, and the interaction between treatment and period effect. Changes in urinary protein excretion, Scr, and Ccr within each group were analyzed by paired $t$-test. Unpaired $t$-test was used to compare the percent changes of urinary protein excretion, Scr, and Ccr between the losartan group and the amlodipine group. Values of $p<$ 0.05 were considered to indicate statistical significance.

\section{Results}

In all patients enrolled during the term from December 1999 


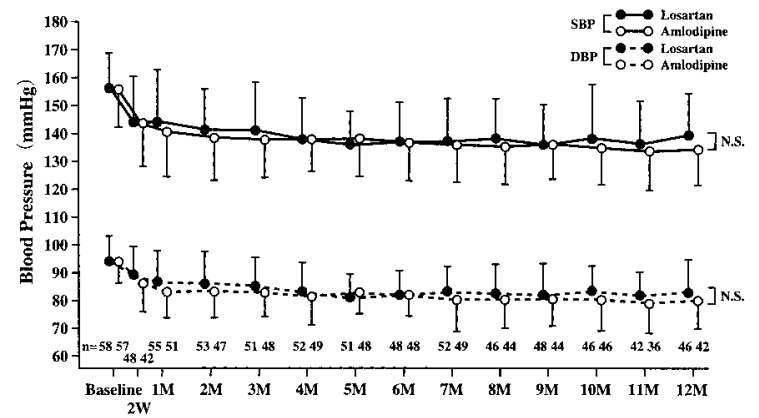

Fig. 2. $S B P$ and $D B P$ changes ( $m m H g$ ) throughout 12 months in groups treated with losartan and amlodipine. Circles and bars indicate the mean and SD. SBP and DBP were not significantly different between the losartan and amlodipine groups.

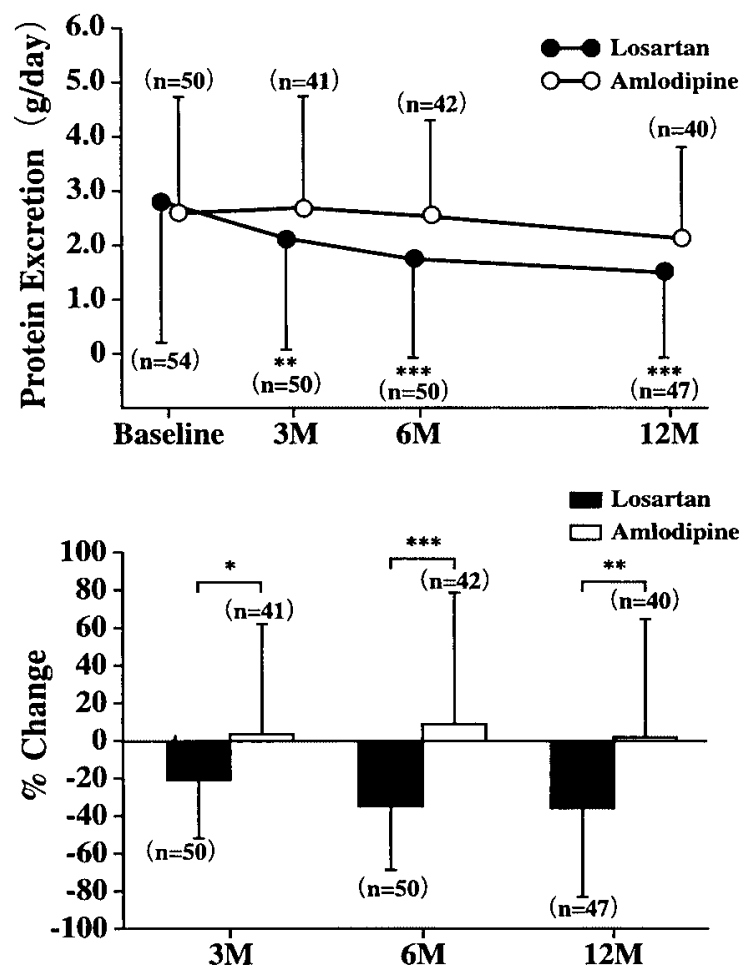

Fig. 3. Changes in 24-h urinary protein excretion (upper panel) and respective percent changes (lower panel) from baseline. Circles and bars indicate the mean and SD. ${ }^{*} \mathrm{p}<0.05,{ }^{* *} \mathrm{p}<0.01,{ }^{* * *} \mathrm{p}<0.001$.

to March 2002, 117 patients (58 for losartan and 59 for amlodipine) were eligible, as their baseline characteristics are shown in Table 1. A large number of patients were diagnosed with chronic glomerulonephritis, including IgA nephropathy. Patients with diabetic nephropathy and hypertensive nephrosclerosis were also included. The characteristics of the two treatment groups were similar. Forty-seven patients in the losartan group and 40 patients in the amlodi-

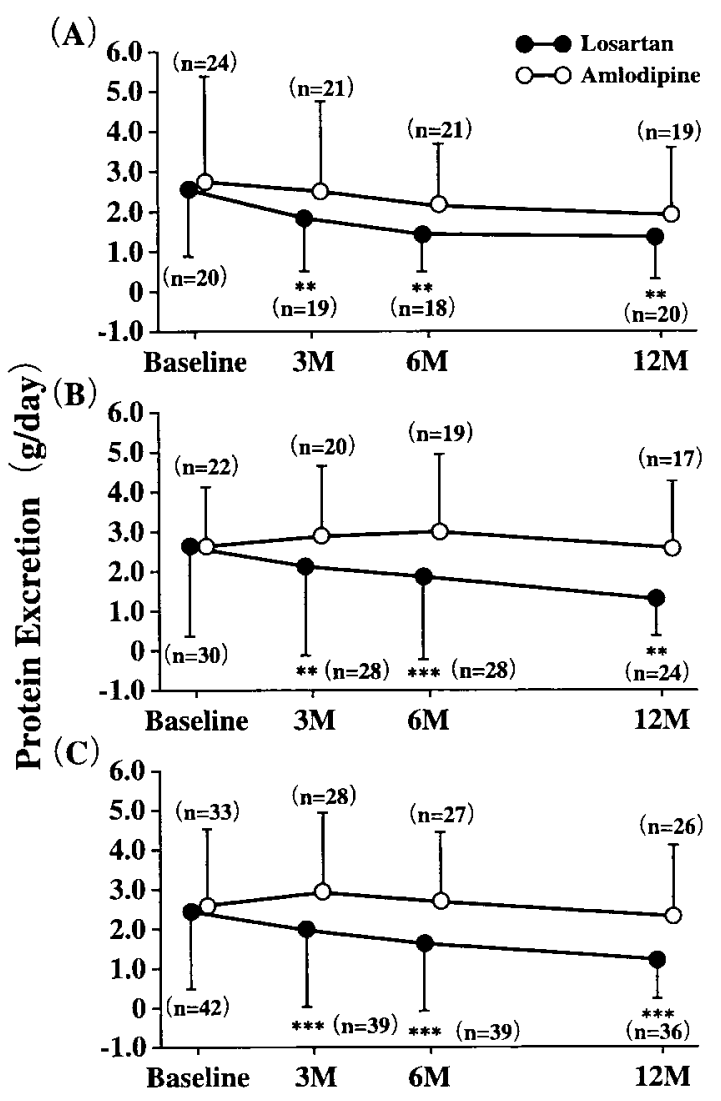

Fig. 4. Changes in urinary protein excretion in patients stratified in response to $B P$ control measured at month 3. (A) $B P<140 / 90 \mathrm{mmHg}$. (B) $B P \geq 140 / 90 \mathrm{mmHg}$. (C) $B P \geq 130 /$ $85 \mathrm{mmHg}$. Note that patients in group $C$ are included in either the group $A$ or $B$ because of respective BP ranges, as a consequence. Circles and bars indicate the mean and $S D$. ${ }^{* *} \mathrm{p}<0.01,{ }^{* * *} \mathrm{p}<0.001$.

pine group completed the 12-month study for measurement of urinary protein endpoint. The dietary compliance assessment of 24-h urinary urea nitrogen plus proteins and sodium showed that, there was no significant difference in total protein and $\mathrm{NaCl}$ intake between the two drug treatment groups at baseline and no change from baseline to month 3, as reported previously (9). At month 12, again, there was no change from baseline and therefore no difference between the losartan group and the amlodipine group in protein intake

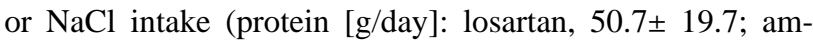

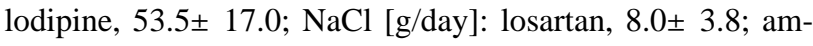

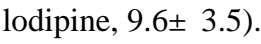

The BP-lowering effect, in both systole (SBP) and diastole (DBP), was similar with losartan and amlodipine. Figure 2 shows changes in SBP and DBP measured at week 2 and at every month. In the losartan group, SBP was reduced from $156.5 \pm 12.2 \mathrm{mmHg}$ at baseline to $139.5 \pm 14.8 \mathrm{mmHg}$ at month 12 ( $-11.3 \pm 9.2 \%$ ), and DBP from $94.0 \pm 9.2 \mathrm{mmHg}$ at baseline to $83.0 \pm 11.7 \mathrm{mmHg}$ at month $12(-12.2 \pm$ $10.8 \%$ ), and in the amlodipine group, the reduction in SBP 


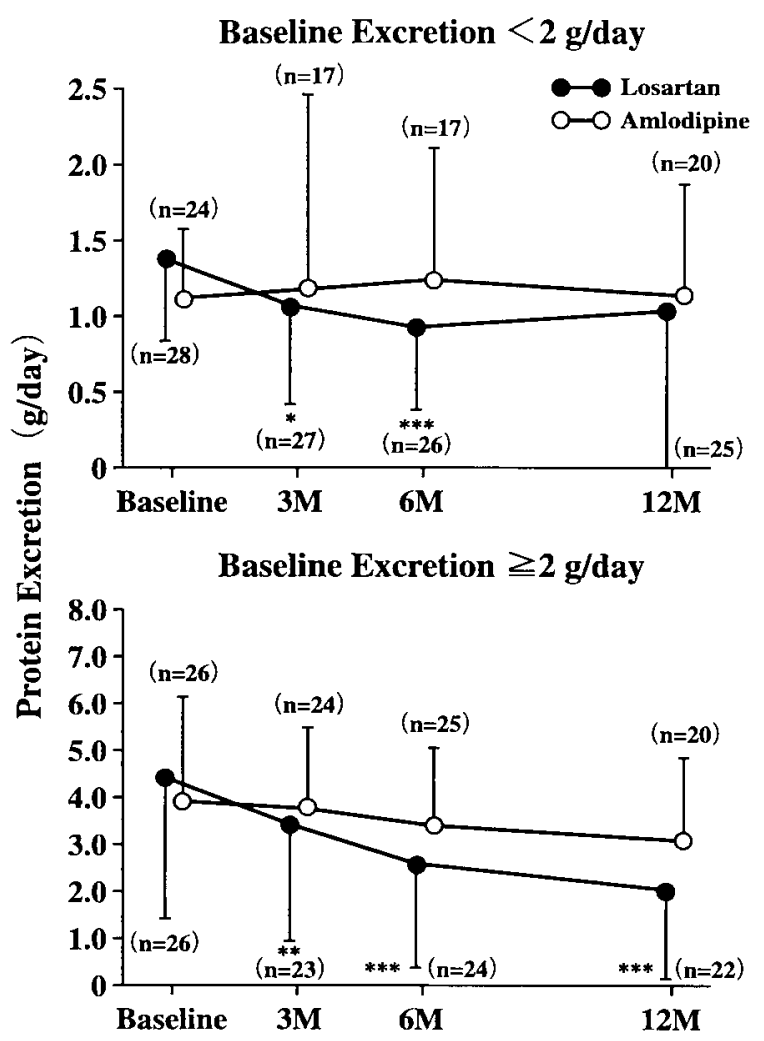

Fig. 5. Changes in urinary protein excretion from baseline in patients stratified into two groups showing proteinuria of $<2 \mathrm{~g} /$ day (upper panel) and $\geq 2 \mathrm{~g} /$ day (lower panel) as measured at baseline. Circles and bars indicate the mean and $S D .{ }^{*} \mathrm{p}<0.05,{ }^{* *} \mathrm{p}<0.01,{ }^{* * *} \mathrm{p}<0.001$.

was from $155.7 \pm 13.6 \mathrm{mmHg}$ at baseline to $134.3 \pm 13.1$ mmHg at month $12(-12.7 \pm 10.0 \%)$, and that of DBP was from $94.1 \pm 7.9 \mathrm{mmHg}$ at baseline to $79.7 \pm 10.1 \mathrm{mmHg}$ at month 12 ( $-15.1 \pm 12.5 \%)$, respectively.

However, urinary protein excretion was significantly reduced only in the losartan group. The upper panel of Fig. 3 shows the change in urinary protein excretion and the lower panel shows the percent change from the respective baselines. The apparent changes in percent were $-20.7 \%$, $-35.2 \%$, and $-35.8 \%$ at months 3,6 , and 12 , respectively. We then analyzed the relationship between BP control and reduction of proteinuria in patients treated with losartan.

The responsiveness to the drug was assessed by BP measured at month 3. In this analysis, patients whose BP was controlled to $<140 / 90 \mathrm{mmHg}$ as well as those whose BP was not controlled at month 3 showed a statistically significant reduction in urinary protein excretion from baseline at each of months 3, 6, and 12. Although the JNC-VI guidelines recommend a BP goal of $<130 / 85 \mathrm{mmHg}$ for hypertensive patients with CKD (12), patients in whom this goal was not achieved still showed a statistically significant reduction in urinary protein excretion by losartan (Fig. 4). In the losartan group with a BP of $<130 / 85 \mathrm{mmHg}$, there was

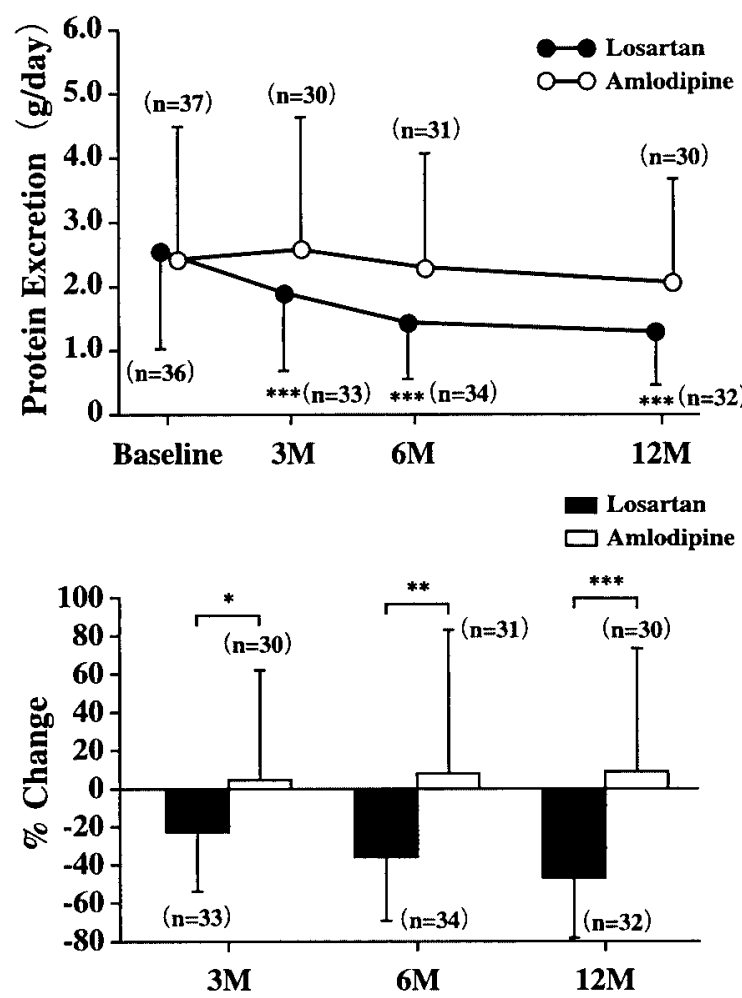

Fig. 6. Changes in urinary protein excretion (upper panel) and respective percent changes (lower panel) in patients with chronic glomerulonephritis. Circles and bars indicate the mean and SD. ${ }^{*} \mathrm{p}<0.05,{ }^{* *} \mathrm{p}<0.01,{ }^{* * *} \mathrm{p}<0.001$.

an apparent reduction in urinary protein excretion, but without statistical significance.

Although at baseline there was no statistically significant difference between treatment groups in the ratio of males to females (Table 1), the number of female patients in the amlodipine group decreased during the study. However, in the losartan group, changes in proteinuria were almost comparable between males and females: $-21.0 \% \quad(n=31)$ and $-20.2 \%(n=19)$ at month $3,-35.5 \%(n=31)$ and $-34.6 \%$ $(n=19)$ at month 6 , and $-35.2 \%(n=29)$ and $-36.9 \%(n=$ 18 ) at month 12 in males and females, respectively. Likewise, although no effect was observed with amlodipine, changes in the amount of proteinuria in males and females were $+7.1 \%(\mathrm{n}=31)$ and $-8.0 \%(n=10)$ at month 3 , $+13.6 \%(n=30)$ and $-4.6 \%(n=12)$ at month 6 , and $-1.5 \%(n=30)$ and $+10.6 \%(n=10)$ at month 12 , respectively.

In order to examine whether the magnitude of proteinuria affected the result of treatments with losartan and amlodipine, we stratified patients into two subgroups: those with proteinuria $<1 \mathrm{~g} /$ day and those with proteinuria $\geq 1 \mathrm{~g}$ /day at baseline. In these subgroups, the change in urinary protein excretion from baseline was not significantly different between the losartan group and the amlodipine group. We next stratified patients with proteinuria levels of $<2 \mathrm{~g} /$ day and 

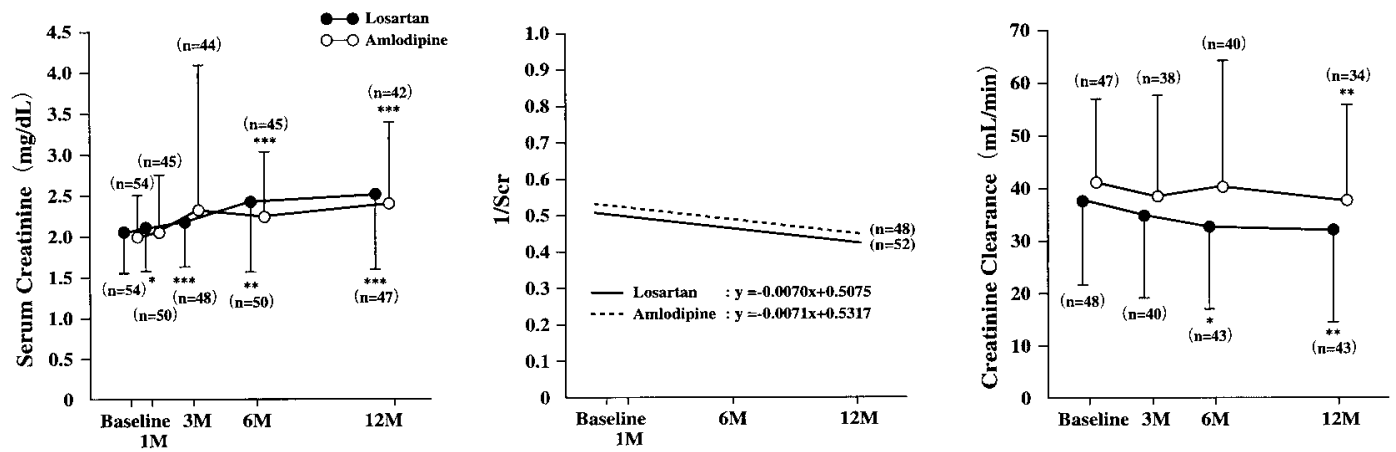

Fig. 7. Changes in Scr (left panel), 1/Scr (middle panel), and creatinine clearance (right panel) in patients treated with losartan for Scr and $1 / S c r$. Circles and bars indicate the mean and $S D .{ }^{*} \mathrm{p}<0.05,{ }^{* *} \mathrm{p}<0.01,{ }^{* * *} \mathrm{p}<0.001$. There was no difference for the slope of $1 / \mathrm{Scr}$ between the losartan and amlodipine group.

$\geq 2 \mathrm{~g}$ /day at baseline. As shown in Fig. 5, the reduction in urinary protein excretion was evident in losartan groups of both $<2$ g/day and $\geq 2$ g/day. Again, amlodipine did not significantly reduce urinary protein excretion in both groups of $<2$ g/day and $\geq 2$ g/day.

With respect to the diagnosis of patients, 38 patients in the losartan group and 41 in the amlodipine group had chronic glomerulonephritis, and 7 in the losartan group and 7 in the amlodipine group had diabetic nephropathy. Analysis of the patients with diabetic nephropathy revealed an apparent decrease from baseline in urinary protein excretion in the two treatment groups, with no statistically significant difference between the groups (data not shown). Analysis of the subgroup with chronic glomerulonephritis exhibited a statistically significant reduction in proteinuria in the losartan group at months 3, 6, and 12. Because amlodipine did not reduce proteinuria in patients with chronic glomerulonephritis, there was a prominent difference in the percent reduction in urinary protein excretion from baseline between the two treatment groups (Fig. 6).

Changes in Ccr and Scr and the slope of 1/Scr did not differ between the two treatment groups. Scr slightly increased from the baseline to month 3 in both groups. Ccr showed a tendency of decline (Fig. 7).

Adverse events considered to be possibly related to the study were reported for increases in aspartate aminotransferase (AST; GOT) (2 cases), alanine aminotransferase (ALT; GPT) ( 1 case) and $\gamma$-GTP ( 4 cases). These changes were mild and the incidence was almost the same between the losartan group and the amlodipine group. An increase in serum uric acid ( 2 cases) was reported in the amlodipine group, but was not observed in the losartan group. Hyperkalemia ranging from 5.1 to $6.9 \mathrm{mEq} / \mathrm{l}$ was reported in the losartan group (3 cases) and in the amlodipine group (2 cases). Two cases of dizziness and 1 case of transient ischemic attack were reported in the losartan and amlodipine groups. No fatal adverse events were observed in either group during the 12-month study.

\section{Discussion}

The present study demonstrated that, in patients with proteinuric CKD and hypertension, losartan effectively reduced proteinuria while amlodipine did not. It is noteworthy that the potency of BP-lowering of losartan and amlodipine was same throughout the entire 12-month study period. Allocation of patients resulted in an almost comparable male to female ratio between the treatment groups at baseline. However, more number of female patients decreased in the amlodipine group than in the losartan group as the study progressed. Consequently, at month 12, in the losartan group, the male/female ratio was $29 / 18$, while in the amlodipine group it was 30/10. Although the losartan group included a greater number of female patients than the amlodipine group at months 3,6 , and 12 , the percent reduction in urinary protein excretion in males was comparable to that in females in the losartan group. Therefore, it was unlikely that a sex hormone such as estrogen played a role in the vascular protection in this study. The fact that a large majority of female patients in the losartan group at baseline were aged ( $22 \mathrm{fe}$ males: 54-59 year-old, 4; in their 60's, 9; in her 70's, 1) may warrant this discussion, because female patients of mid-50's or older were probably undergoing menopause.

In the present study, we first stratified patients into 3 subgroups with regard to BP reduction measured at month 3 . The first 3 months was a meaningful period because no other drugs was added on either losartan or amlodipine during this period. Losartan reduced both BP and proteinuria. However, it was also true that not all patients responded to losartan to reach the goal $\mathrm{BP}$ of $<130 / 85 \mathrm{mmHg}$ that was recommended by the JNC-VI (12). In fact, the goal BP was achieved in only 8 patients in the losartan group and 13 patients in the amlodipine group. It was expected that patients who reached the goal BP of $<130 / 85 \mathrm{mmHg}$ would show a prominent decrease in urinary protein excretion. However, there was no significant change in urinary protein excretion from baseline in either the losartan group or the amlodipine group, al- 
though in the losartan group urinary protein tended to decrease. The reason for this finding is unclear; however, since the number of patients in each group was very small, this might be the reason why we failed to demonstrate statistical significance, especially in the losartan group. Nonetheless, even in patients who did not accomplish the BP goal, reduction of proteinuria was evident. Likewise, patients who achieved a BP of $<140 / 90 \mathrm{mmHg}$ represented the anti-proteinuric effect of losartan. A striking evidence was that patients who did not accomplish the level of BP $<140 /$ $90 \mathrm{mmHg}$ also showed the reduction in proteinuria, the degree of which did not largely differ from those in the group of $\mathrm{BP}<140 / 90 \mathrm{mmHg}$.

It must not be a conclusion that, in patients with CKD and hypertension, it is sufficient to pursue a reduction in proteinuria without a corresponding reduction in BP. It should be emphasized that BP control is still an important strategy in treating patients with CKD and hypertension, as the JNC-VI recommends. Our results can only be taken to indicate that losartan may still be effective to reduce proteinuria, even if $\mathrm{BP}$ can not reach the BP goal of the JNC-VI guidelines (12). In this aspect, losartan should be used in clinical practice under the condition of exerting anti-hypertensive effect. The goal BP of $<130 / 80 \mathrm{mmHg}$ for patients with CKD which was currently recommended by JNC-VII guideline (13) should also be taken into account. Thus, the use of losartan will bring better outcomes for patients with CKD and hypertension with concomitant BP control.

Although we failed to find a difference in anti-proteinuric effect between losartan and amlodipine when patients were stratified with the baseline proteinuria of $<1 \mathrm{~g} /$ day and $\geq 1 \mathrm{~g} /$ day, further stratification with levels of $<2 \mathrm{~g} /$ day and $\geq 2 \mathrm{~g} /$ day clearly demonstrated the anti-proteinuric effect of losartan at all assay points in the group of $\geq 2 \mathrm{~g} /$ day. These results suggest that losartan was effective to reduce severe proteinuria of probably glomerular origin. The effect was still observable in the group of $<2 \mathrm{~g} /$ day at months 3 and 6 , but was not statistically significant at month 12 , probably due to a wide range of standard deviation from the mean value. Very recently, Tojo et al. (14) reported that, in streptozotocin-induced diabetic rats, intervention of actions of angiotensin II by either an ACE inhibitor or an angiotensin II antagonist restored albumin reabsorption in the proximal tubules without changing blood glucose via restoration of the expression of megalin, a glycoprotein responsible for reabsorption of proteins in the proximal tubules, resulting in the reduction in urinary protein excretion. The authors suggested that expression of megalin is suppressed in the proximal tubules when the kidney is impaired for tubular dysfunction. This evidence may explain, at least in part, our results on the effect of losartan on proteinuria, a part of which may be of tubular origin.

While the RENAAL study (8) was conducted in patients with type 2 diabetes, a large majority of the patients enrolled in the present study had chronic glomerulonephritis includ- ing cases of immunoglobulin $\mathrm{A}$ ( $\operatorname{Ig} \mathrm{A})$ nephropathy. In these patients, losartan effectively reduced urinary protein excretion. Chronic glomerulonephritis involves many factors in its etiology, and the complicated proteinuria is not solely a result of hyperfiltration of glomeruli. Rather, remodeling of the glomerulus must be considered. Since amlodipine did not affect the protein excretion in such patients, the present result is of particular interest in considering the direct actions of angiotensin II on the structure and functions of glomeruli. Patients with diabetic nephropathy in the losartan group and the amlodipine group were 7 and 5 on the day of start and only 5 and 4 patients completed the study, respectively. Because of this limited number of diabetic patients, there was no statistically significant change in urinary protein excretion in either drug treatment group, although the magnitude of the mean reduction of urinary protein ranged from $-30 \%$ to $-50 \%$. We therefore cannot conclude from these results that these drugs have no anti-proteinuric effect in patients with diabetic nephropathy.

With respect to the pharmacotherapy of patients with $\mathrm{CKD}$, the therapeutic benefit of interfering with the actions of angiotensin II has been extensively documented with ACE inhibitors over the last decade. The breakthrough evidence that direct blockade of angiotensin II receptors protects the kidney in patients with type 2 diabetic nephropathy was provided by the RENAAL study ( 8 ) with losartan, and the IDNT study with irbesartan (15).

Recent publications provided evidences that the angiotensin II receptor antagonist candesartan was effective in Japanese patients with type-2 diabetic nephropathy, with a dose as low as $4 \mathrm{mg} /$ day to prevent aggravation of proteinuria (16), or reduce urinary protein excretion by combination therapy with amlodipine (17), supporting previous evidences on losartan and irbesartan for diabetic nephropathy. The results of our present study provide the additional information useful in clinical practice, that losartan is effective not only for patients with type 2 diabetic nephropathy, but also those with a variety of types of CKD. Nakao et al. (18) recently studied the effect of combination therapy and monotherapy with losartan and the ACE inhibitor trandolapril in patients with non-diabetic renal disease. They demonstrated that losartan as well as trandolapril effectively lowered urinary protein excretion, although the combination of these two drugs exerted a more favorable effect on proteinuria. Taken together, the antiproteinuric effect of losartan may play a major role in its renoprotective effect.

The therapeutic benefit of losartan for kidney diseases in comparison to other antihypertensive drugs is still not fully explained. As is indicated in the JNC-VI (12) and JNC-VII (13) guidelines and several clinical reports, aggressive blood pressure control is mostly important. On the other hand, many clinical trials have demonstrated that blood pressure control is not the only factor pertinent for renoprotection; rather, ACE inhibitors and angiotensin II receptor antagonists provide additional benefit in patients with kidney dis- 
eases.

The RAS is now well understood to be involved in the pathogenesis of renal impairment independent of its vasoconstrictive actions, inducing disturbance of glomerular and tubular functions. The direct actions of angiotensin II in the kidney include an increase in tubular sodium reabsorption and an influence on glomerular filtration rate (GFR), but morphopathological changes such as accumulation of extracellular matrix and mesangial cell proliferation and hypertrophy $(19,20)$ are of more importance for pathogenesis of renal impairment. These concepts clearly constitute the theory of usefulness of blocking the actions of angiotensin II in kidney diseases. Although the UK Prospective Diabetes Study (UKPDS) (21) concluded that the effects of ACE inhibitor captopril and the $\beta$-blocker atenolol were similar in reducing the risk of macrovascular and microvascular complications related to type 2 diabetes, the African-American Study of Kidney Disease and Hypertension (AASK) Study (22), which compared the effects of the ACE inhibitor ramipril, the calcium channel blocker amlodipine, and the $\beta$-blocker metoprolol on the progression of hypertensive renal disease in African-Americans, showed that ramipril induced a slower decline in GFR and a lower risk of clinical end points compared to amlodipine.

The mechanism and mode of action of losartan and amlodipine to explain the exertion of different effect of renoprotection are not thoroughly explained and are controversial. Documents are available to explain the renoprotective efficacy of calcium channel blockers, including amlodipine. However, whether calcium channel blockers exert unique antiproteinuric effects is still controversial. In the AASK Study (22), proteinuria was not decreased with amlodipine. The Japan Multicenter Investigation of Antihypertensive Treatment for Nephropathy in Diabetes (J-MIND) study (23) reported that nifedipine retard and enalapril had a similar effect on nephropathy in hypertensive type 2 diabetic Japanese patients, but albumin excretion rate was not reduced with either drug despite the effective BP lowering. Kumagai et al. (24) reported the comparative evaluation of amlodipine with ACE inhibitors enalapril or captopril for renoprotective effect in hypertensive patients with renal dysfunction. They concluded that the effect of 1-year treatment with amlodipine on renal function was likely the same as that of ACE inhibitors. They also showed that urinary protein excretion tended to be reduced by either ACE inhibitor or amlodipine, but without statistical significance. These evidences suggest that, while a strong argument has been made for proteinuria as a risk factor for progression of renal disease (25), there is still a discrepancy between renoprotection as a final goal and urinary protein excretion as an important clinical sign for renal dysfunction.

There is thus a strong body of evidence suggesting that the pathways by which angiotensin II aggravates renal functions are mediated by angiotensin II type 1 ( $\left.\mathrm{AT}_{1}\right)$ receptors. Calcium channel blockers act to dilate the microvasculature, im- proving regional circulation by regulating the voltage-dependent calcium channels. The blockade of angiotensin II receptors results in a reduction in renal perfusion pressure in addition to dilation of the efferent arterioles to a greater extent than the afferent arterioles because of their different manner of constriction in response to angiotensin II, and thus angiotensin II antagonists reduce the glomerular filtration pressure to same extent. On the other hand, the action of angiotensin II is not solely to constrict macrovascular and microvascular trees, but a variety of cellular actions are evident. A number of reports have described roles of angiotensin II through $\mathrm{AT}_{1}$ receptors to produce extracellular matrix as well as to stimulate proliferation and/or hypertrophy of many types of cells, via the direct stimulation of mitogen-activated protein kinase (MAPK), transforming growth factor (TGF- $\beta$ ), nuclear factor $(\mathrm{NF}-\kappa \mathrm{B})$, induction of proto-oncogenes, and so on $(19,20,26)$. Thus, although there is still no confirmatory theory, wider biological functions of angiotensin II may explain the diversity of renoprotective activity of the two drugs without depending on their BP lowering efficacy. The precise mechanism of the action of these drugs should be further investigated.

In the present study, there was no change in Ccr either in the losartan or amlodipine groups. Andersen et al. (27) conducted a 2-month, randomized, double-blind cross-over clinical trial to evaluate the effect of losartan and the ACE inhibitor enalapril in patients with type 1 diabetic nephropathy, and reported that angiotensin II blockade reduced urinary protein excretion without changing GFR. In the RENAAL study (8), the risk of a doubling of the serum creatinine concentration in the losartan treatment group and the placebo group was almost the same until 12 months from initiation of the study, although the reduction in urinary protein excretion was observed in the losartan treatment group within 6 months. The IDNT study (15) with irbesartan also reported no difference in the change in serum creatinine in comparison to placebo and amlodipine within 12 months. Thus, it is likely that effects on proteinuria and on Ccr differ in response to blockade of angiotensin II receptors, although the reason is not explained. The present study was completed at 12 months. It might be expected that longer-term treatment of the patients with CKD and hypertension with losartan would have more beneficial effects on renal functions such as improvement of GFR in patients beyond the effect to reduce proteinuria.

In conclusion, a term of total 12 months treatments of Japanese patients with proteinuric CKD and hypertension with losartan reduced proteinuria more effectively than amlodipine, although BP lowering effect was not different between the two drug-treated groups. Since the effect was beyond the blood pressure control, losartan is effective in patients with CKD manifesting proteinuria and hypertension. 


\section{Acknowledgements}

The authors appreciate the investigators listed below, in this study. Investigators: T. Konta, S. Takasaki, T. Matsunaga, T. Ishimitsu, H. Matsuda, S. Komatsumoto, T. Utsugi, S. Tomono, S. Nagase, K. Yamagata, K. Hirayama, K. Mase, K. Aoyagi, M. Kobayashi, H. Nakamura, H. Kikuchi, Y. Maeda, T. Okado, H. Nakamoto, S. Sugawara, Y. Handa, C. Iwahashi, T. Kashiwagi, S. Matsunobu, T. Hosoya, G. Tokudome, Y. Utsunomiya, H. Yamamoto, H. Okonogi, T. Shigematsu, Y. Miyazaki, K. Funabiki, S. Horikoshi, M. Fukui, H. Ohmuro, K. Tashiro, T. Saruta, K. Hayashi, T. Nakao, T. Okada, H. Ohi, T. Fujita, K. Nakabayashi, S. Ishizuka, A. Hasegawa, S. Mizuiri, K. Sakai, T. Suzuki, C. Ibuki, H. Yamanaka, T. Tadera, K. Nagasawa, A. Yoshimura, E. Kinugasa, H. Morita, S. Uda, S. Hara, Y. Ubara, H. Katori, F. Takemoto, T. Tagami, M. Yokota, A. Yamada, Y. Matsushita, T. Sugimoto, H. Tagawa, Y. Komatsu, T. Ohiwa, M. Futatsuyama, K. Kitazawa, T. Shibata, K. Honda, M. Endo, A. Ando, K. Ikeda, M. Yasuda, T. Ito, T. Takahashi, Y. Hori, M. Fukagawa, T. Oose, T. Shinoda, H. Yoshimoto, H. Miyakawa, N. Makita, R. Kuriyama, K. Muroga, T. Ito, W. Kitajima, T. Suzuki, H. Tsuganezawa, S. Wakai, T. Ida, Y. Chida, R. Ando, K. Yamanouchi, Y. Yamashita, M. Suenaga, K. Asano, M. Ogawa, N. Hayama, H. Rinno, Y. Kimura, M. Ogura, T. Mochizuki, T. Hasegawa, T. Nakazato, S. Owada, T. Maeba, T. Sato, T. Fujino, S. Kondo, Y. Kobayashi, T. Matsuo, N. Takagi, Y. Toya, N. Hirawa, M. Kihara, T. Murasawa, Y. Sakai, G. Yasuda, N. Ogawa, M. Iyori, T. Nishikawa, H. Tsuji, H. Sugiura, H. Ito, A. Saito, A. Soyama, T. Takei, Y. Ikeda, T. Iwamoto, K. Hasegawa, T. Isozaki, M. Sakakima, T. Hatta, Y. Bito, K. Maki, Y. Kawano, T. Inenaga, H. Nakahama, K. Kamide, T. Horio, S. Nakamura, O. Sasaki, S. Suga, S. Takiuchi, T. Kuwahara, S. Ueda, A. Tanaka, T. Doi, A. Mizuno, S. Ohashi, H. Abe, K. Kawahara, S. Kawashima, J. Minakuchi, K. Ishihara.

\section{References}

1. Burnier M, Brunner HR: Comparative antihypertensive effects of angiotensin II receptor antagonists. J Am Soc Nephrol 1999; 10: S278-S282.

2. Aros C, Remuzzi G: The rennin-angiotensin system in progression, remission and regression of chronic nephropathies. J Hypertens 2002; 20 (Suppl 3): S45-S53.

3. Jafar TH, Schmid CH, Landa L, et al: Angiotensin-converting enzyme inhibitors and progression of nondiabetic renal disease. Ann Intern Med 2001; 135: 73-87.

4. Remuzzi G, Bertani T: Is glomerulosclerosis a consequence of altered glomerular permeability to macromolecules? Kidney Int 1990; 38: 384-394.

5. Powrie JK, Thomas S: Microalbuminuria: should lowering albumin excretion be a therapeutic goal? Int J Clin Pract 1999; 53: 492-493.

6. Fassbinder W, Quarder O, Waltz A: Treatment with carvedilol is associated with a significant reduction in microalbuminuria: a multicentre randomized study. Int J Clin Pract 1999; 53: 519-522.

7. de Boer E, Navis G, Wapstra F-H, de Jong PE, de Zeeuw
D: Effect of proteinuria reduction on prevention of focal glomerulosclerosis by angiotensin-converting enzyme inhibition is modifiable. Kidney Int 1999; 56 (Suppl 71): S42S46.

8. Brenner BM, Cooper ME, de Zeeuw D, et al: Effects of losartan on renal and cardiovascular outcomes in patients with type 2 diabetes and nephropathy. N Engl J Med 2001; 345: 861-869.

9. Iino Y, Hayashi M, Kawamura T, et al: Interim evidence on the renoprotective effect of the angiotensin II receptor antagonist losartan versus the calcium channel blocker amlodipine in patients with chronic kidney disease and hypertension: a report of Japanese Losartan Therapy Intended for the Global Renal Protection in Hypertensive Patients (JLIGHT STUDY). Clin Exp Nephrol 2003; 7: 221-230.

10. Proceedings of International Conference on Harmonization. Statistical Principles for Clinical Trials. February 5, 1998.

11. Maroni BJ, Steinman TI, Mitch WE: A method for estimating nitrogen intake of patients with chronic renal failure. Kidney Int 1985; 27: 58-65.

12. Joint National Committee on Prevention, Detection, Evaluation, and Treatment of High Blood Pressure: The sixth report of the Joint National Committee on Prevention, Detection, Evaluation, and Treatment of High Blood Pressure. Arch Intern Med 1997: 157: 2413-2446.

13. Chobanian AV, Bakris GL, Black HR, et al: The seventh report of the Joint National Committee on Prevention, Detection, Evaluation, and Treatment of High Blood Pressure. JAMA 2003; 289: 2560-2572.

14. Tojo A, Onozato ML, Kurihara H, Sakai T, Goto A, Fujita $\mathrm{T}$ : Angiotensin II blockade restores albumin reabsorption in the proximal tubules of diabetic rats. Hypertens Res 2003; 26: $413-419$.

15. Parving H-H, Lehnert H, Bröchner-Mortensen J, et al: The effect of irbesartan on the development of diabetic nephropathy in patients with type 2 diabetes. $N$ Engl $\mathrm{J} \mathrm{Med}$ 2001; 345: 870-878.

16. Maruyama S, Hirano T, Sakaue T, Okada K, Ikejiri R, Adachi M: Low-dose candesartan cilexecil prevents early kidney damage in type 2 diabetic patients with mildly elevated blood pressure. Hypertens Res 2003; 26: 453-458.

17. Kuriyama S, Tomonari H, Tokudome G, et al: Antiproteinuric effects of combined antihypertensive therapies in patients with overt type 2 diabetic nephropathy. Hypertens Res 2002; 25: 849-855.

18. Nakao N, Yoshimura A, Morita H, Takeda M, Kayano T, Ideura T: Combination treatment of angiotensin-II receptor blocker and angiotensin-converting-enzyme inhibitor in non-diabetic renal disease (COOPERATE): a randomized controlled trial. Lancet 2003; 361: 117-124.

19. Weir MR, Dzau VJ: The renin-angiotensin-aldosterone system: a specific target for hypertension management. Am J Hypertens 1999; 12: 205S-213S.

20. Nishimura H, Ichikawa I: What have we learned from gene targeting studies for the renin angiotensin system of the kidney? Intern Med 1999; 38: 315-323.

21. UK Prospective Diabetes Study Group: Efficacy of atenolol and captopril in reducing risk of macrovascular and microvascular complications in type 2 diabetes: UKPDS 39. BMJ 1998; 317: 713-720. 
22. Agodoa LY, Appel L, Bakris GL, et al: Effect of ramipril $v s$. amlodipine on renal outcomes in hypertensive nephroscrerosis: a randomized control trial. JAMA 2001; 285: 2719-2728.

23. Baba S, The J-MIND Study Group: Nifedipine and enalapril equally reduce the progression of nephropathy in hypertensive type 2 diabetics. Diabetes Res Clin Pract 2002; 54: 191-201.

24. Kumagai H, Hayashi K, Kumamaru H, Saruta T: Amlodipine is comparable to angiotensin-converting enzyme inhibitor for long-term renoprotection in hypertensive patients with renal dysfunction: a one-year, prospective, randomized study. Am J Hypertens 2000; 13: 980-985.

25. Jafar TH, Stark PC, Schmid CH, et al: Proteinuria as a modifiable risk factor for the progression of non-diabetic renal disease. Kidney Int 2001; 60: 1131-1140.

26. Mezzano SA, Ruiz-Ortega M, Egido J: Angiotensin II and renal fibrosis. Hypertension 2001; 38: 635-638.

27. Andersen S, Tarnow L, Rossing P, Hansen B, Parving H-H: Renoprotective effects of angiotensin II receptor blockade in type 1 diabetic patients with diabetic nephropathy. Kidney Int 2000; 57: 601-606. 